\title{
Design of a Tracking Welding Robot Automation System for Manufacturing of Steam and Heating Boilers
}

\author{
${ }^{* 1}$ Süleyman Ersöz(0000-0002-7534-6837), ${ }^{1}$ Ahmet Kürşad Türker(0000-0001-6686-9241), ${ }^{1}$ Adnan Aktepe(0000-0002-3340- \\ 244X), ${ }^{2}$ İrfan Atabaş(0000-0002-1519-2979), ${ }^{1}$ Melda Kokoç(0000-0003-2035-9777) \\ ${ }^{a}$ Kırıkkale University, Department of Industrial Engineering, 71450, Yahşihan, KIRIKKALE \\ sersoz40@hotmail.com, kturker@yahoo.com, aaktepe@gmail.com, meldabagbasi@gmail.com \\ ${ }^{\mathrm{b}}$ Kırıkkale University, Department of Computer Engineering, 71450, Yahşihan, KIRIKKALE \\ iatabas@yahoo.com
}

Received Date: 05.12.2017 Accepted Date: 31.05.2018

\begin{abstract}
For satisfying customers companies want to respond to customer requests on time. At the same time, they expect production process to be completed with low cost and low loss. For this reason, the importance of mechanization and automation in production sector has increased. As a result, companies have begun to give more importance to robotic systems, which are the basic components of automation systems. Despite the likelihood of mistakes caused by physiological and mental states of humans, these systems can perform operations precisely without any variability. In this study, an application was carried out for the automation of welding process of industrial type boilers in different sizes and features. For products of which standard measurements or welding operations are difficult to perform manually, a robotic system was proposed in which measurement and welding operations can be performed automatically. In addition, operators are prevented from exposure to gas and light via the proposed system which enables a safer working condition.
\end{abstract}

Keywords: Automation, Image Processing, Robotic System, Welding Process

\section{INTRODUCTION}

In recent years, developing technology and changing processes of life have forced companies to re-examine business policies, to determine targets that meet the developing conditions and to reach these targets. The most important factors that distinguish companies from their competitors today are that they can adapt to changing conditions and respond to customer demands with flexible organizational structure. Due to changing production and consumption conditions, importance of mechanization and automation in production sector has increased and many companies have begun to give more places to automation systems in production line. One of the basic elements of automation systems is robotic systems. With these systems, operations that require sensibility or power are performed quickly and accurately. It is a process that leaving companies in manufacturing sector from traditional methods based on labour power and then moving to automation systems, requires cost. Some of companies cannot move to automation systems either because of lack of vision, or because they do not want to bear extra costs. One of manufacturing sectors experiencing this problem is steam and hot water boiler sector, where production is still being done using conventional methods. The most critical process in boiler production is welding process. Welding is said to be process of joining two or more pieces of metal in such a way that they are not separated under high temperature [1, 2]. Welding in manufacturing sector is widely carried out by workers. However, there are many negative situations in welding which carried out by human hands. Some of these are:

i. Welding operator directly influences welding quality,

ii. Welding process is not always the same and continuous quality,

iii. There are negative effects on human health,

iv. Finding welding specialist is difficult, etc.

Today, organizations that use welding connections in their production have realized need to use robotic arm technology in welding operations that enables mass production. In automation sector, there are solutions available for standard production. However, these systems are not suitable for businesses where non-standard products are produced. 
Determination of points to be welded has different difficulties according to material to be welded. Several methods for 3D scanning have been proposed in literature. $\mathrm{Xu}$ et al. [3] extracted the 3D model of objects by integrating 2D classification algorithms via Kinect sensor. Another study that uses the Kinect sensor to perform 3D modelling of industrial products is study of Kahn et al. [4]. Kinect sensor technology which has been used since 2014 cannot produce depth information on reflective surfaces, transparent surfaces, or deep areas. Saygili et al. [5] filled these empty depth areas with learning algorithms. A limited number of studies about automatic welding systems which used 3D imaging systems have been carried out. In one of these studies prototype capable of 3 axes linear welding was produced [6]. In another study, Qian et al. 7], proposed a method of detecting edges of metal parts using image processing techniques. But, proposed method is not suitable for real-time applications and produces solutions for nonlinear boundaries. Several other studies have been carried out to automate welding operations. In order to control and operate process of GMAW, a neural network based on generalized delta rule was adopted in Yang and et al. [8]'s study. In entrance layer of neural network algorithm, width and depth of weld joint were chosen as neurons. Input variables (width and depth of weld joint) were obtained via image information. In output layer, voltage, weld speed and wire feed rate are symbolized as neurons. In Starke, et al. [9]'s study, they presented strategies, and research results in applying robot operating system and robot operating system-based solutions. This system was proposed to overcome existing technical gaps via integration of selforganization capabilities and autonomous path planning. In Borovik, et al. [10]'s study, algorithm synthesis for industrial robot control was carried out. Electron -beam projector with plasma emitter was used as operating tool. Parameters of emission power provided melting of additive material were determined.

In our study, a prototype which automatically welds by defining coordinates of the welding points of different scales and geometries, was designed and produced. Developed system offers innovative solutions compared to systems produced in automation sector in order to be compatible with different products. In developed system, object to be welded is scanned horizontally, vertically or circularly in 3 dimensions and joints on object are automatically detected using artificial intelligence algorithms. Combining these points with welding is done with a torch integrated into a cartesian robot arm that can move in 5 axes. Following advantages are provided by produced system;

- Development of automation and integrated software system in production with new welding technology,

- The ability to respond quickly to the different needs of customers with increased flexibility in production,

- Providing stability in product quality through intelligent manufacturing technology,

- Preventing the problems that affect the health of the workers caused by the source,

- Reducing injuries or deaths which were caused by boiler explosion, by minimizing production faults in pressurized boilers.

Programmable robot welding systems are being used effectively in advanced manufacturing sectors for standard production. However, in the manufacturing sector where non-standard production is carried out, welding operations are performed entirely manually by workers. In addition to adverse effects to health of workers, manual welding leads to poor welding quality. It is possible to provide worker safety, and also to automatically perform welding operations with an automation system so that standard and reliable welding operations can be performed. In this study, it was ensured that these adverse conditions were removed. In addition, unique qualities of this study are as follows;

- In the developed system, imaging system which allows 3D modelling of not only horizontal but also, vertical and circular areas was used.

- Generated welding automation system is a selfprogrammable structure.

- In this system, motion capability of torch was increased by using a 5-axis Cartesian arm so that it was not only linear but welded in free-form or circular shapes.

- Production of such a system which has automated welding capability has been first application for Turkey in this field.

- Unlike standard automatic welding systems, because this system enables versatile 3D imaging and welding with a 5-axis robot arm, allowing system to automatically weld many products in the manufacturing industry, not just in the boiler.

\section{DESIGN OF WELDING AUTOMATION SYSTEM}

Steps followed when creating the proposed robotic welding system are as shown in in Figure 1. Basic Process steps are explained below. 


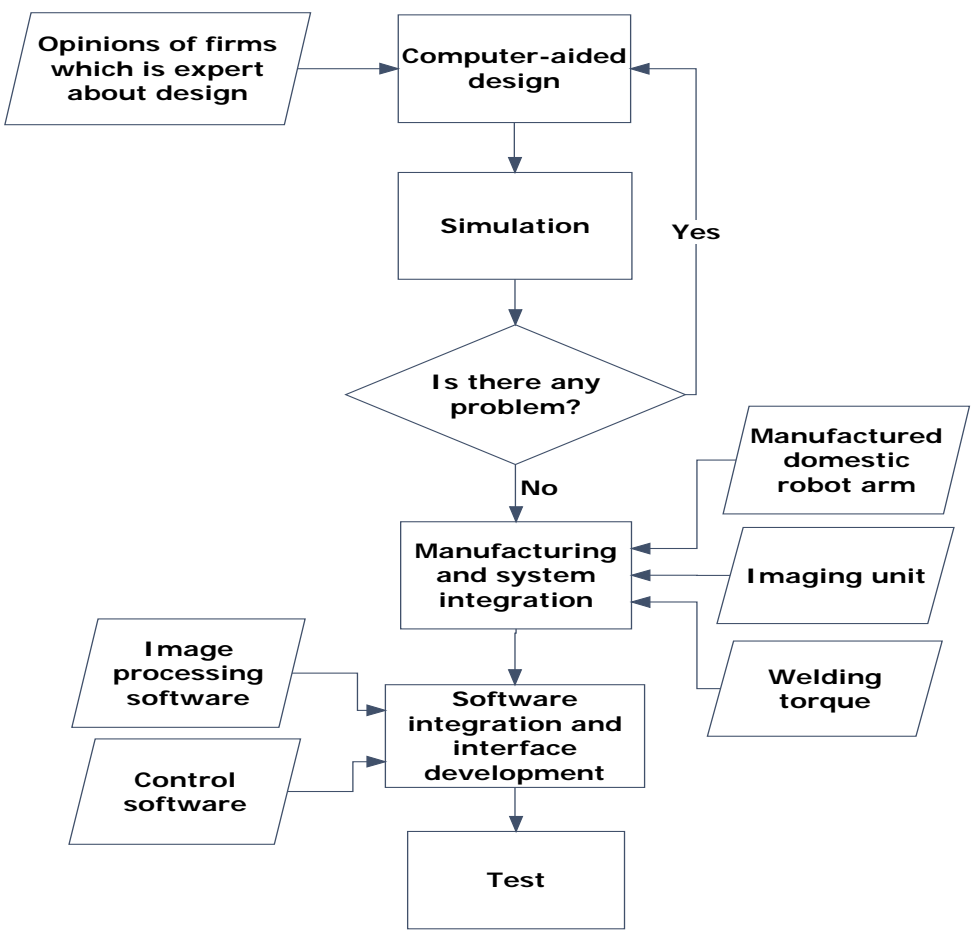

Fig. 1. Flow Diagram of Proposed System

\subsection{Design}

To create a machine roughly, the stages are

i. Imagining machine,

ii. Drawing sketch shape,

iii. Ensuring that mechanism works,

iv. Dimensioning elements,

v. Drawing assembly drawings,

vi. Making and testing prototype machine.

All processes up to production stage are called design [11, 12]. Designer identifies material selection, manufacturing method, dimensions, and tolerances in design phase. This stage requires more technical experience. Knowledge that designer can use, such as stress formulas, material properties, production methods, is required. When a satisfactory design is achieved, analysis is appropriate. If design is good, manufacturing can be done. Often design is insufficient after the prototype production because of unsatisfactory and inadequate material, and is returned to the draft design stage $[13,14,15]$.

Since movement system used in the study has a cartesian structure, this system was designed again in the computer environment. It was tried to determine problems that can be encountered after designing system with simulations during designing. For mechanical design of system, collaborations were made with companies specialized in design. Designed system consists of 5 axes. $\mathrm{x}$ and $\mathrm{y}$ axes are shown in Figure 2. 3rd, 4th, and 5th axes are located on the robot arm. 3rd axis allows robot arm to move up and down, while 4th and 5th axes are used to make arm movements. At the end of axis 5 , welding torch is present.

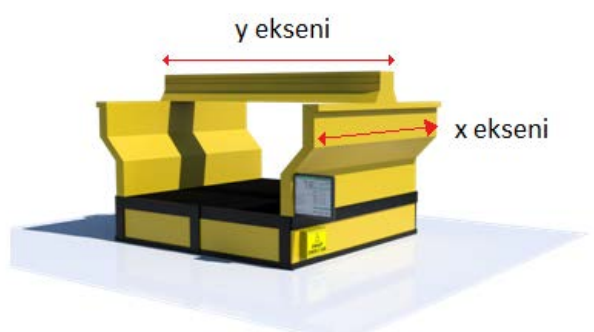

Fig. 2. Front view

\subsection{Manufacturing and System Integration}

After the section shown in Figure 2 was manufactured, assembly of robot arm used in this system was carried out as shown in Figure 3. Robot arm used in system was manufactured with local opportunities. An imaging unit was also placed on robot arm along with welding torch. Camera, lens and filter are included in this unit. After the design stage, this design was produced with a company. We also exchanged ideas about design with company working in manufacture of mechanical components.

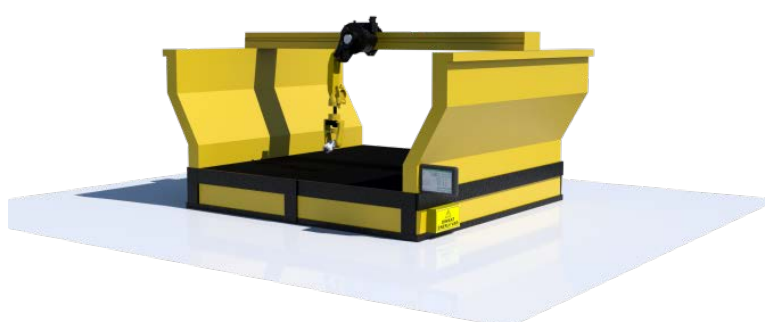

Fig. 3. View after installation 


\subsection{Imaging System}

Image processing is a different process from "signal processing" which is the process of capturing, measuring and evaluating data, then transforming it into a readable form in another device or transferring it from one electronic environment to another electronic environment [16]. Preprocessing applied to images for image processing reduces the noise (fogging, resolution, and bad view) on the images. For this, low, medium and high level operations are applied to the images. In low level operations, the reality of input and output images is provided by filtering. For medium level operations, splitting and recognition operations are performed for the recognition and classification of objects in images. High-level operations involve analysis of images to recognize objects in images. By analysing images in computer, the image contents of the objects in the images are detailed. Then, image processing is performed with this detailing step [17, 18].

In the study, surface of object to be welded should be scanned and surface structure must be visualized in 3D. There are different methods in literature to extract 3D model. In this study, because of the low cost, a 3D model was extracted with a laser line light and a camera that displays this light shown in Figure 4. Imaging system consists of a linear laser light $(635 \mathrm{~nm})$, a camera and a near (NIR) (600-650nm) optical band pass filter to be placed in front of the camera.

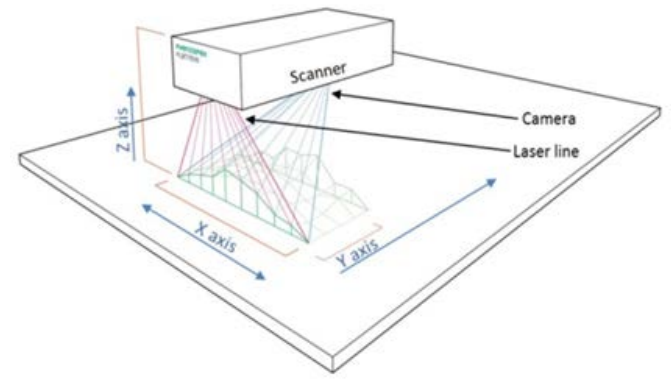

Fig. 4. Drawing of 3D scanner [19]

In the 3D imaging system, when the horizontal axis is referenced (Figure 5), the camera was assembled with a horizontal metal plate with $\varphi$ angle and the laser light source is assembled with a horizontal metal plate with $\theta$ angle. The reflection of the laser beam, which occurs on the object, is displayed on the camera by providing that the linear light to fall on the object to be displayed. When coordinates of object relative to camera axis are extracted, camera parameters that are considered are viewing angle, the size of point formed in image, and size of generated image.

$\mathrm{X}, \mathrm{y}, \mathrm{z}$ are coordinates desired to determine, $\mathrm{d}$ is the distance between camera and light source, $\mathrm{u}$ and $\mathrm{v}$ are dimensions of pixel, $r$ is the distance from the scanned pixel to imaginary square. Based on position and dimensions of target pixel on captured image, 3D coordinates $\mathrm{X}, \mathrm{Y}$, and Z of object corresponding to this pixel are found by Equation 1-6 [20].

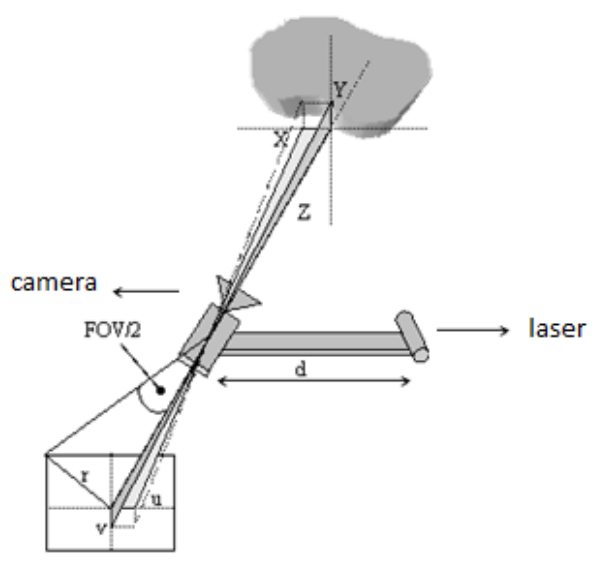

Fig. 5. Determining coordinates of object from camera image [20]

$$
\begin{aligned}
& d \varphi_{x}=\arctan \left(\underset{r}{\operatorname{u}} \tan \left(\frac{F O V}{2}\right)\right) \\
& d \varphi_{y}=\arctan \left(\frac{v}{r} \tan \left(\frac{F O V}{2}\right)\right) \\
& L=2 \tan \left(\frac{F O V}{2}\right) / \sqrt{w^{2}+h^{2}} \\
& Z=d \frac{\cos (\arctan (u L)) \sin (\pi-\theta)}{\sin ((\pi-\theta)+\varphi+\arctan (u L))} \\
& Y=Z v L \\
& X=Z u L
\end{aligned}
$$

During image processing phase, data of image processed by camera is transmitted to data matrix. After transferring to matrix, missing or noisy data in dataset are cleared and transferred to torch.

To sum up the imaging process: Imaging system consists of a laser, a camera, a special lens and an industrial computer. Cartesian motion system consists of a module that can move on 5 different axes, a welding machine placed on this module and a panel with all controls of the system. After cartesian motion system was completed, imaging system was integrated. When system is run, imaging system, which is placed on cartesian system, first takes an image of material to be welded. With developed methods, locations to be welded are determined and these places are shown from user panel to operator. An option was added to software so that system can be continued to operate without operator's approval if requested. Then, coordinates of points to be welded are determined. Lastly, these coordinates are sent to prepared cartesian system. Welding process is started with the torch located on the cartesian system.

\subsection{Software Integration and Interface Development}

There are two softwares in system. One of these is image processing software which detects the places to be welded. 
With this software, the locations to be welded and the coordinates of these places were determined. Other software is control software that makes movement of mechanical system. After coordinates of locations to be welded with image processing software were determined these coordinates were sent to control software. In control software, G-codes of coordinates coming from

image processing software was extracted and sent to control card of cartesian system. Two systems were integrated with each other thereby entire system is automatically operated. An understandable interface program was also developed to ensure that entire control of system can be controlled by the operator. Thanks to this interface, points to be welded can be seen by the operator before welding is done. If operator selects the "automatic welding" option from interface, system can start automatic welding without operator approval. All transactions made with prepared interface are also recorded. Thus, necessary reporting can be done about operation of system.

\subsection{Testing}

In testing stage system is tried or assessed manually or automatically to determine whether it meets specified requirements or to determine the difference between expected and observed results. After stages of design, manufacturing, imaging, integration and interface development, testing was started. At this stage, operations shown in Figure 7 are performed individually to test system. By testing weld points, control engineer make feedback about it. At this point, which is final stage of test processes in project, control is provided by a Fuzzy Expert System algorithm. System's mobility, image acquisition and related parameters and temperature are inputs of fuzzy expert system. Feedback of quality control engineer about control processes constitutes knowledge base composed of decision rules of fuzzy expert system.

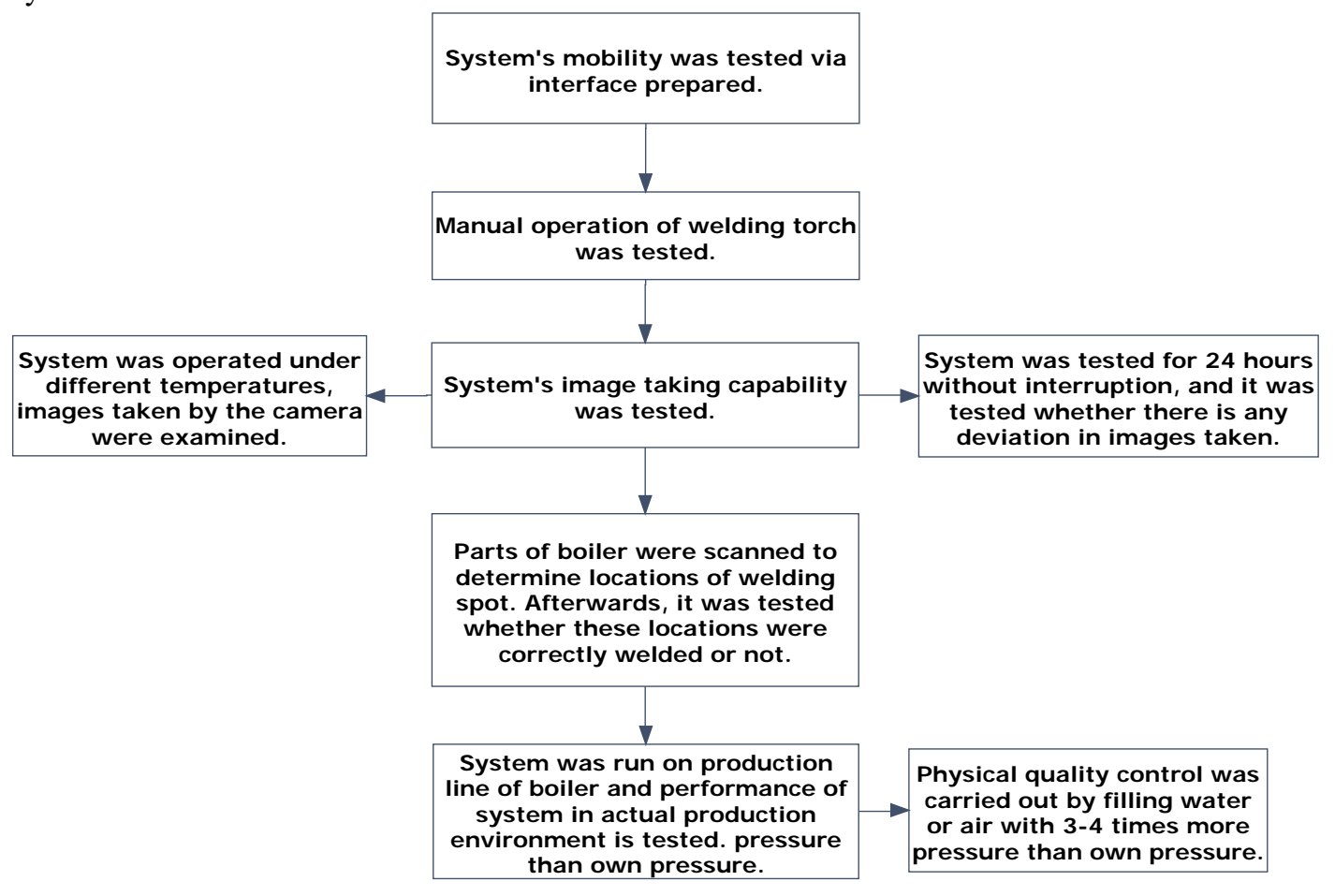

Fig. 7. Operations in testing stage

\section{RESULTS AND DISCUSSION}

In this study, an intelligent welding robot design is developed. The system is based on automated processes for welding operations. With the help of the system developed, welding operations can be conducted automatically which brings many advantages such as flexibility, technological improvement, safer production and better quality products.

With developed system, a production company has several advantages in terms of;

- Flexibility: The company is more flexible than past because now it can reply to customers' requirements quickly. Production rate is increased thanks to automation.

- Technology: System enables workers, especially engineers, to develop new algorithms and to broaden horizon of them.

- Occupational health and safety: Production is safer in terms of human health. Welding process is completely carried out by robot.

- Quality: Defects caused by human errors is minimized. Whole system can be monitored automatically.

In addition, thanks to 5-axis design system and integration with intelligent imaging system, system can be used not 
only in boiler manufacturing but also in different manufacturing sectors.

\section{REFERENCES}

[1] Yang, S. M., Cho, M. H., Lee, H. Y., Cho, T. D., "Weld line detection and process control for welding automation. Measurement Science and Technology”, 18 (3), 819, 2007.

[2] Özkan S.S., Karayel D., Atalı G., Gökbayrak İ., "Esnek Algılayıcı Kontrollü Robot El Tasarımı ve Gerçeklenmesi”, Akademik Platform Mühendislik ve Fen Bilimleri Dergisi (APJES), 5 (3), 35-40, 2017.

[3] Xu D., Cai J. Cham T.J., Fu P., Zhang J., "KinectBased Easy 3D Object Reconstruction”, Lecture Notes in Computer Science, 7674, 476-483, 2012.

[4] Kahn S., Bockholt U., Kuijper A., Fellner D. W., "Towards precise real-time 3D difference detection for industrial applications”, Computers in Industry, 64 (9), 1115-1128, 2013.

[5] Saygili G., Balim C., Kalkan H., Hendriks E.A., "Hierarchical Grid-Based Learning Approach for Recovering Unknown Depths in Kinect Depth Maps”, International Conference on Image Analysis and Recognition, Póvoa de Varzim, Portugal, 2013.

[6] Ersöz, S., Türker, A., K., "İz Süren Kaynak Otomasyonu" (Welding Automation with Tracing), KOSGEB Project, 2013.

[7] Qian X., Yang L., Lou P., “The autonomous detection of sheet metal parts using image Processing”, International Journal of Advanced Manufacturing Technology, DOI: 10.1007/s00170-015-7946-9, 2015.

[8] Yang, Sang-M., "Weld line detection and process control for welding automation", Measurement Science and Technology, 18 (3), 819, 2007.

[9] Starke, G. et al., "Self-Organization and SelfCoordination in Welding Automation with Collaborating Teams of Industrial Robots", Machines, 4 (4), 23, 2016.
[10] Borovik, V., "Industrial Robot Automation in Solving Non-Vacuum Electron-Beam Welding Problems", MATEC Web of Conferences, 79, EDP Sciences, 2016.

[11] Renner, G. Anikó E., "Genetic algorithms in computer aided design." Computer-Aided Design 35 (8), 709-726, 2003.

[12] Boothroyd, G., "Product design for manufacture and assembly", Computer-Aided Design 26 (7), 505-520, 1994.

[13] Regli, William C., Vincent A. C., "Managing digital libraries for computer-aided design", Computer-Aided Design, 32 (2), 119-132, 2000.

[14] Wang, H., et al. "Computer aided fixture design: Recent research and trends", Computer-Aided Design, 42 (12), 1085-1094, 2010.

[15] Wang, H., Yiming K. R., "Case based reasoning method for computer aided welding fixture design", Computer-Aided Design, 40 (12), 1121-1132, 2008.

[16] Gonzalez R. C., Woods R. E., "Digital Image Processing", 3th Ed., 1-7, U.S.A., New Jersey, Prentice Hall, 2007.

[17] Çomak, B., Beycioğlu, A., Başyiğit, C., Kılınçarslan, Ş., "Beton teknolojisinde görüntü işleme tekniklerinin kullanımı", (Use of image processing techniques in concrete technology), In 6th Intenational Advanced Technologies Symposium (IATS’11), 2011.

[18] Erkan E., Özçalık H.R., Yılmaz Ş., "Görüntü İşleme Teknikleri Kullanılarak İnsan Hareketlerini Algılayan Akıllı Güvenlik Sistemi Tasarımı", Akademik Platform Mühendislik ve Fen Bilimleri Dergisi (APJES), 3 (1), 1-6, 2015.

[19] Kjaer, K. H., Carl-Otto O., "3D laser triangulation for plant phenotyping in challenging environments", Sensors, 15 (6),13533-13547, 2015.

[20] "Determining coordinates of object from camera image", Available from: http://georgepavlides.info/research/LaserScanningAndTrian gulation.php, (Access date: 01.12.2017). 